\title{
Correlation between Individual Dietary Diversity Score and Nutrients Adequacy Ratio in the Rural Community
}

\author{
Indresh Kumar', *, Madhulika Gautam² \\ ${ }^{1}$ Associate Professor, Dayalbagh Educational Institute (Deemed University), Agra-282005 \\ ${ }^{2}$ Research Scholar, Dayalbagh Educational Institute (Deemed University), Agra-282005 \\ *Corresponding Author: Indresh Kumar, Village-Charaiya, PO-Shambhua, Dist-Kanpur Nagar-209308; \\ Email ID: kumar.indresh@hotmail.com ; Mobile No.8574741072
}

\begin{abstract}
Dietary diversity indicators can serve as a proxy for diet quality and have shown an association with Dietary diversity indicators can serve as a proxy for diet quality and have shown an association with nutrient adequacy at the individual level; it is positively correlated with indicators of micronutrients adequacy in several types of study. The main objective of this study is to examine the nutrient adequacy ratio and its relationship with the individual dietary diversity score in the rural community. The relationship between individual dietary diversity score and nutrients adequacy was assessed with and without the minimum quantity food groups intake restriction. Data was collected through the 24 hours dietary recall schedule and dietary diversity questionnaire by applying 24 hours recall method in randomly selected 491 individuals from the rural areas of Uttar Pradesh state of India. Individual dietary diversity score was measured using the nine food groups system, suggested by Food and agriculture organization, US. An analysis of the relationship with sixteen nutrients was assessed through the Microsoft excel data analysis functions. It was found that iron and niacin intake had moderate-positive co-relation with individual dietary diversity scores, and a weak positive correlation with calcium, thiamine, riboflavin, vitamin-A, potassium, zinc, protein, vitamin-C, folates were found with no minimum quantity intake of the food groups. A negative correlation between sodium, phosphorus, and magnesium intake was noted; and there was no correlation noted with fat and energy. After fixing the minimum intake quantity of the food groups, the relationship between the dietary diversity score and the nutritional accuracy was strengthened. The association of micronutrients with the Individual Dietary Diversity Score was shown to be strong after applying minimum 15 grams intake quantity restriction of the food groups.
\end{abstract}

Keywords: Diet diversity; food variety; nutrients adequacy; community nutrition

\section{INTRODUCTION}

Dietary quality assessment of a community is to identify the magnitude and geographical dispersal of malnourishment and to prepare an efficient plan to control and eradicate them to sustain good nutrition. ${ }^{1}$ The use of food groups in appropriate quantities is important for a healthy society, due to lack of good quality food the population getting malnourished. There are many different types of Dietary Quality Indicators (DQI) to assess dietary quality such as (I) food or food group-based indicators (II) nutrient-based indicators and (III) combination indicators. Diet Diversity (DD) is a food group-based indicator, and it is universally recognized as a key component of healthy diets. ${ }^{2}$ Published literature on DD, with a focus on the conceptual and operational issues 
related to its measurement in developing countries, was highlighted by several researchers and showing the linear correlation between diet quality. ${ }^{3}$ Dietary Diversity Score (DDS) was a useful proxy indicator of nutrient adequacy amongst the rural population. Indeed, the performance of the indicators is improved when considering the quantities of food consumed. ${ }^{4}$

The nutritional assessment is done to obtain data about the prevalence and geographic distribution of nutritional disorders within a community or a specified population group. It can also be used to recognize high-risk groups and to evaluate the role of diverse epidemiological issues in nutritional deficiency. ${ }^{5}$ The methods of dietary assessment of community are time taking and expensive, whereas Individual Dietary Diversity Score (IDDS) can prove to be easy and less expensive. ${ }^{6} \mathrm{DD}$ is measured at the household level (household dietary diversity score) and assesses at an individual level called the Individual Dietary Diversity Score (IDDS) and is positively correlated with nutrients adequacy in general diets and is a proxy indicator of a healthy $\operatorname{diet}^{7}$. Correlation between IDDS and the nutrition adequacy ratio has been assessed by many studies. IDDS is a substitution indicator of diet quality proved by many kinds of research ${ }^{8}$ The DDS increases by one point, after use of the food groups in small amounts, without significant improvement in the nutrients adequacy in many kinds of studies. 9, 10 The main objective of this study is to examine the nutrient adequacy ratio and its relationship with the individual dietary diversity score in the rural community. The relationship between individual dietary diversity score and nutrients adequacy was also assessed with and without 15 grams Minimum Food-group Intake Restriction (MFIR). ${ }^{11,12}$

\section{MATERIAL AND METHODOLOGY}

Local of Study: Eight villages of Banda and Kannauj districts were purposively selected from the different agro-climatic zone of the Indian state of Uttar Pradesh.

Sample selection: A Sample of 491 individuals was selected with the systemic random sampling method from the selected villages, 180 adolescent boys and girls of $\geq 13-<18$ age and 311 adult men and women over the age of $\geq 18-<60$ are included. Ethical clearance was obtained from the institution's ethics committee. Only volunteer participants were included in the study and written consent was obtained from the participants before collecting the information.

Data collection: Personal conversations and observation methods were used to collect the data, and the researcher administrated all schedules and questionnaires.

Institute of Medicine (US), Committee on Dietary Risk Assessment was suggested before collection of good quality data by the using Dietary intake schedule (24 hours recall) method is needed to learn techniques carefully. 13 Therefore, the researcher had learned this technique efficiently from the ICMR-NIN, Hyderabad, and also had two years of experience for this recall method.

This questionnaire was responded to by the person who cooks the previous day's food. A recall interview typically requires 40 to 50 minutes to complete, but it may take considerably longer if different types of foods were consumed.

Variables: IDDS is an independent variable that was influenced by the 16 types of dependent variables such as vitamin $\mathrm{A}$, calcium, riboflavin, potassium, vitamin $\mathrm{C}$, niacin, iron, carbohydrate, thiamine, protein, folates, zinc, fat, phosphorus, magnesium, and sodium.

Data analysis: Microsoft excel data pack was used for the quantitative data analysis, in which the given functions were used to find the average, percentage, standard deviation, t-test, and correlation.

Assessment IDDS: A questionnaire was used for the measurement of IDDS developed by FAO's and also suggested guidelines were followed. Nine food groups were used for the measurement of IDDS, this is a simple way in which the food groups taken on the previous day are summed and arrive at individual food scores, which ranged from 1 to 9 (with 1 being the lowest score and 9 highest) (Table 1). The score was assessed by two times, the first time without MFIR and another time with 15 grams MFIR.

Table 1. The procedure of IDDS measuring

\begin{tabular}{|l|l|}
\hline Step-1 & $\begin{array}{l}\text { The total number of food groups consumed by the individual. Values for A through } \mathrm{L} \text { will be } \\
\text { either " } 0 \text { " or " } 1 \text { ". } \\
\text { IDDS (1-9) }=\text { Sum }(\mathrm{A}+\mathrm{B}+\mathrm{C}+\mathrm{D}+\mathrm{E}+\mathrm{F}+\mathrm{G}+\mathrm{H}+\mathrm{I})\end{array}$ \\
\hline Step-2 & Average IDDS= Sum (IDDS)/Total number of Individuals \\
\hline
\end{tabular}

Assessments of Nutritional intake: The food intake was assessed by using a one-time through24hours dietary recall method and summarized in the groups through using a customized sheet of Microsoft excel. The calculated data was compared with Recommended Dietary Intake (RDI) has given by Indian Council for Medical Research (ICMR).

Nutrients Adequacy Ratio (NAR): The NAR is the ratio of a subject's intake to the current recommended allowance for each sex and age 
category for a given nutrient. Nutrient adequacy of 16 nutrients was estimated.

NAR=Actual nutrient intake of a nutrient (per day) Recommended Daily Allowance of the nutrient

The NAR is equal to the ratio of an individual's nutrient intake to the Recommended Daily Allowance (RDA) 2020 for his or her age and sex and can be represented as a ratio. ${ }^{14}$

Assessment of correlations: The CORREL function in the Microsoft Excel data pack was used to find Pearson's correlation coefficient between two variables. The possible range of values for the correlation coefficient is -1.0 to 1.0 . Anytime the correlation coefficient is greater than zero, it's a positive relationship, and a value $\geq$ of 0.75 is showing a strong positive correlation. Conversely, anytime the value is less than zero, it's a negative relationship. A value of zero indicates that there is no relationship between the two variables.

Recommendations: It was tried to understand the correlations between the quality of food group intake and nutrients adequacy but big data will be required to prove that in a more reliable way. It needed to be studied in-depth; how many variables were influencing the IDDS but in this study, it was difficult to control all food intake affecting factors. The relationship between IDDS and nutrients adequacy should be assessed with different amounts of MFIR and without MFIR.

\section{RESULTS AND DISCUSSION}

Consumption of food groups: The food intake data were collected by the 24-hour recall method. People mostly used cereals $(100.00 \%)$, oil $(97.00 \%)$, and tubers $(88.71 \%)$ in the general diet. Ogan meat\& fish $(3.86 \%)$ and eggs $(4.83 \%)$ were least used by individuals on the previous day without MFIR. Dark green and leafy vegetables were used $34.80 \%$ by the people without MFIR, while $22.83 \%$ with MFIR. The relationship between IDDS and nutrients adequacy got stronger with 15 grams MFIR (Table 2).

Table 2. Consumption of different food groups on the previous day $(n=491)$

\begin{tabular}{|c|l|c|c|c|c|}
\hline \multirow{2}{*}{ S. No } & \multirow{2}{*}{ Food groups } & \multicolumn{2}{|c|}{ Without MFIR } & \multicolumn{2}{c|}{ With 15-gramsMFIR } \\
\cline { 3 - 5 } & & $\mathbf{n}$ & $\mathbf{\%}$ & $\mathbf{N}$ & \% \\
\hline 1 & Starchy staple & 491 & 100.00 & 491 & 100.00 \\
\hline 2 & Pulses, legumes, nuts, and seeds & 255 & 52.00 & 199 & 40.45 \\
\hline 3 & Organ meat and fish & 44 & 8.86 & 19 & 3.86 \\
\hline 4 & Roots and tubers & 405 & 82.45 & 361 & 73.55 \\
\hline 5 & Dark green \& leafy vegetables & 171 & 34.80 & 112 & 22.83 \\
\hline 6 & Other Vit-A rich food \& vegetables & 191 & 38.91 & 109 & 22.26 \\
\hline 7 & Eggs & 63 & 12.83 & 24 & 4.83 \\
\hline 8 & Milk and milk products & 390 & 79.51 & 376 & 66.51 \\
\hline 9 & Fat and oil-based items & 491 & 100.00 & 491 & 100.00 \\
\hline
\end{tabular}

IDDS: Studies in different areas have shown that an improvement in the IDDS is related to the improvement of nutrients adequacy. There was a reduction in the IDDS after MFIR, the average IDDS was reduced from 5.09 to 4.31 . The highest of $28.11 \%$ of respondents without MFIR was obtained 5 IDDS, while there were $32.59 \%$ of the respondents got a score of 4 with MFIR.In general, the highest of $28.11 \%$ of respondents without MFIR was used 5 food groups, while there were $32.59 \%$ of the respondents were used 4 food groups with MFIR (Table 3).

Table 3. Distribution of IDDS $(n=491)$

\begin{tabular}{|c|c|c|c|c|}
\hline \multirow{2}{*}{ IDDS } & \multicolumn{2}{|c|}{ Without MFIR } & 15-grams MFIR & \% \\
\cline { 2 - 5 } & $\mathbf{N}$ & 0.00 & 0 & 0.00 \\
\hline 1 & 0 & 2.65 & 17 & 3.46 \\
\hline 2 & 13 & 12.63 & 119 & 24.24 \\
\hline 3 & 62 & 18.94 & 160 & 32.59 \\
\hline 4 & 93 & 28.11 & 79 & 16.09 \\
\hline 5 & 138 & 23.22 & 74 & 15.07 \\
\hline 6 & 114 & 8.96 & 21 & 4.28 \\
\hline 8 & 44 & 3.87 & 15 & 3.05 \\
\hline 9 & 19 & 1.63 & 6 & 1.22 \\
\hline Collectively & 8 & Average 4.31 and SD 1.72* & Average 5.09 and SD 1.65* \\
\hline
\end{tabular}


NAR: The NAR is equal to the ratio of an individual's nutrient intake to the current recommended allowance of the nutrient for his or her age and sex, and can be represented as a ratio or as a percentage (Table 4). NAR value one shows that the intake of the indexed nutrient is balanced; it is a ratio with the recommended Dietary Allowances 2020 and the amount of nutrients intake. ${ }^{12,13}$ There were five nutrients with a NAR below 0.75 , the intake of vitamin A was getting the least, whose NAR was 0.40 and the highest intake was sodium with NAR 2.42 .

Table 4. Average NAR of nutrients

\begin{tabular}{|c|l|c|c|c|}
\hline S. No. & Variables & Mean & SD & NAR \\
\hline 1. & Vitamin A & 266.94 & 426.83 & 0.40 \\
\hline 2. & Calcium & 398.89 & 313.85 & 0.50 \\
\hline 3. & Riboflavin & 0.79 & 0.57 & 0.55 \\
\hline 4. & Potassium & 2344.91 & 823.66 & 0.67 \\
\hline 5. & Vitamin C & 29.08 & 26.70 & 0.73 \\
\hline 6. & Niacin & 11.72 & 4.94 & 0.76 \\
\hline 7. & Iron & 17.65 & 9.40 & 0.81 \\
\hline 8. & Carbohydrate & 389.60 & 110.00 & 0.84 \\
\hline 9. & Thiamine & 1.03 & 0.94 & 0.88 \\
\hline 10. & Protein & 51.39 & 17.34 & 0.90 \\
\hline 11. & Folates & 170.44 & 89.11 & 0.91 \\
\hline 12. & Zinc & 10.87 & 4.98 & 0.96 \\
\hline 13. & Fat & 0.75 & 41.42 & 1.31 \\
\hline 14. & Phosphorus & 1213.57 & 473.98 & 1.82 \\
\hline 15. & Magnesium & 553.54 & 324.82 & 2.14 \\
\hline 16. & Sodium & 4826.00 & 5360.00 & 2.42 \\
\hline
\end{tabular}

Correlation between IDDS and nutrition adequacy with and without MFIR

Many types of research have already been done to find out the relation between IDDS and nutrients accuracy, and the significant relationship between micronutrients and DDS, it was also proved earlier in many kinds of research. ${ }^{17,} 18,19$ In this research, improvement in the IDDS, the use of micronutrients was also improved, there were significant differences were found in eleven micronutrients out of thirteen without MFIR but after the MFIR the relationship was strengthened. There was no strongness with the correlation between without MFIR and with MFIR of the two energy-giving macronutrients out of three. ${ }^{20}$ The rootedness between calcium and IDDS without MFIR was weak $(r=0.41)$, when compared to the same with MFIR the correlation was getting better $(\mathrm{r}=.65)$. The relationship between calcium and IDDS without MFIR was weak $(r=0.41)$, when compared to the same with MFIR the correlation was getting better $(r=.65)$. There was no strong correlation between the IDDS and nutrients adequacy founded without MFIR, whereas with MFIR there was a strong positive relation for iron and niacin were renowned (Table 5).

Table 5. Correlation between IDDS and nutrients intake (r-value*)

\begin{tabular}{|c|l|c|c|}
\hline S. No. & Variables & No minimum intake restriction & Minimum 15-gram intake restriction \\
\hline 1. & Carbohydrate & 0.00 & 0.00 \\
\hline 2. & Fat & 0.00 & 0.00 \\
\hline 3. & Folates & 0.04 & 0.13 \\
\hline 4. & Vitamin C & 0.08 & 0.13 \\
\hline 5. & Protein & 0.09 & 0.15 \\
\hline 6. & Zinc & 0.13 & 0.17 \\
\hline 7. & Vitamin A & 0.14 & 0.23 \\
\hline 8. & Potassium & 0.14 & 0.22 \\
\hline 9. & Riboflavin & 0.15 & 0.33 \\
\hline 10. & Thiamine & 0.18 & 0.32 \\
\hline 1. & Calcium & 0.41 & 0.65 \\
\hline 12. & Niacin & 0.56 & 0.75 \\
\hline 13. & Iron & 0.59 & 0.76 \\
\hline 14. & Magnesium & -0.31 & -0.25 \\
\hline 15. & Phosphorus & -0.09 & -0.12 \\
\hline 16. & Sodium & -0.11 & -0.13 \\
\hline
\end{tabular}


Nutrients showing a positive relationship had a stronger association after MFIR, but nutrients showing a negative relationship had no significant change after MFIR. Magnesium, phosphorus, and sodium without MFIR were showing correlation Rvalues $-0.31,-0.09$, and -0.11 respectively, which renovate $\mathrm{r}$-value was $-0.25,-0.12$, and -0.13 respectively after the MFIR.

\section{CONCLUSION}

This research assessed the correlation between IDDS and nutrients adequacy with 15 grams MFIR and without MFIR. A weak positive correlation with calcium, thiamine, riboflavin, vitamin-A, potassium, zinc, protein, vitamin-C, folates was found between IDDS and nutrients adequacy without MFIR, with MFIR the relationship got stronger. There was no strong correlation between the IDDS and nutrients adequacy founded without MFIR, whereas with MFIR there was a strong positive relation for iron $(\mathrm{r}=0.75)$ and niacin $(r=0.76)$ were renowned. Energy and fat were not found to have any co-relation with IDDS, whereas negative co-relation between sodium, phosphorus, magnesium intake was founded. IDDS is increasingly included in food and nutrition security surveys to provide indicators of household food access or individual dietary quality. The food items being used were arranged in 9 food groups, but at the local level food groups should be categorized based on the availability of food items in the area and nutrients need in the local population. IDDS may be a better way to measure DQI with MFIR because restriction enhances the relationship and shows the quality more efficiently.

\section{Author's Contributions}

The corresponding author participated in the design of the study, data collection, data analysis, data interpretation, and the draft of the manuscript. Madhulika Gautam assisted in data interpretation and critical reconsideration of the manuscript. All authors read and permitted the final manuscript.

\section{Financial Disclosure}

Financial assistance has not been received from any agency or institution for this study.

\section{Conflict of Interest}

The authors declare that they have no competing interests.

\section{Acknowledgements}

The authors are thankful to the participants for their passionate cooperation. Finally thanks to the multiple unnamed reviewers who provided feedback that helped to improve this paper. Financial support has not been received from any agency or organization for this study.

\section{REFERENCES}

1. Visser J, McLachlan MH, Maayan N, Garner P. Community-based supplementary feeding for food insecure, vulnerable and malnourished populations- An overview of systematic reviews. Cochrane Database Syst Rev 2018;11(11):CD010578.

2. Food, Agriculture Organization of the United Nations (FAO). International Fund for Agricultural Development (IFAD), World Food Programme (WFP). The State of Food Insecurity in the World: The Multiple Dimensions of Food Security. Rome: FAO, 2013.

3. Gómez G, Nogueira Previdelli Á, Fisberg RM, Kovalskys I, Fisberg M, Herrera-Cuenca M, Cortés Sanabria LY, Yépez García MC, Rigotti A, Liria-Domínguez MR, Guajardo V, Quesada D, Murillo AG, Brenes JC. Dietary Diversity and Micronutrients Adequacy in Women of Childbearing Age: Results from ELANS Study. Nutrients 2020;12(7):1994.

4. Rathnayake KM, Madushani P, Silva K. Use of the dietary diversity score as a proxy indicator of nutrient adequacy of rural elderly people in Sri Lanka. BMC Res Notes 2012;5:469.

5. Geng S, Ma J, Liu S, Zhang J, Sheng X. Lack of Dietary Diversity Contributes to the Gaps in Micronutrient Status and Physical Development between Urban and Rural Infants. Iran J Public Health. 2018;47(7):958966.

6. Kennedy G. Ballard T. and Dop MC. Food and Agriculture Organization of the United Nations. Guidelines for Measuring $\mathrm{HH}$ and Individual Dietary Diversity. 2010.

7. Nithya DJ, Bhavani RV. Factors that may limit the value of dietary diversity and its association with nutritional outcomes in preschool children in high burden districts of India. Asia Pac J Clin Nutr. 2018;27(2):413420.

8. Kennedy G, Pedro MR, Seghieri C, Nantel $\mathrm{G}$, Brouwer I. Dietary diversity score is a useful indicator of micronutrient intake in non-breastfeeding Filipino children. J Nutr 2017;37:1-6.

9. Arimond M, Wiesmann D, Becquey E, Carriquiry A, Daniels MC, Deitchler M, Fanou-Fogny N, Joseph ML, Kennedy G, Martin-Preval Y, Torheim LE. Simple food group diversity indicators predict micronutrient adequacy of women's diets in 5 diverse, resource-poor settings. J Nutr 2010;140(11):2059S-69S.

10. Foote JA, Murphy SP, Wilkens LR, Basiotis $\mathrm{PP}$, Carlson A. Dietary diversity increases the probability of nutrient adequacy among adults. J Nutr 2004;134:1779-85. 
11. Ducrot $\mathrm{P}$, Méjean C, Aroumougame V, Ibanez $\mathrm{G}$, Allès B, Kesse-Guyot E, Hercberg S, Péneau S. Meal planning is associated with food variety, diet quality, and body weight status in a large sample of French adults. Int J Behav Nutr Phys Act. 2017;14(1):12.

12. National Institute of Nutrition. Dietary Guidelines for Indians. Hyderabad: National Institute of nutrition; 2020. Available from: https://www.nin.res.in/RDA_Full_Report_202 $0 . h t m l$

13. Singh A, Gupta V, Ghosh A, Lock K, GhoshJerath S. Quantitative estimates of dietary intake with special emphasis on snacking pattern and nutritional status of free-living adults in urban slums of Delhi: impact of nutrition transition. BMC Nutr. 2015;1:22.

14. Kominiarek MA, Rajan P. Nutrition Recommendations in Pregnancy and Lactation. Med Clin North Am. 2016;100 (6):1199-1215.

15. Bhattacherjee S, Datta S, Ray K, Mukhopadhyay DK. Nutrient adequacy and its correlation in a sub-Himalayan region of West Bengal, India. J Family Med Prim Care. 2016;5(2):314-319.
16. Gombart AF, Pierre A, Maggini S. A Review of Micronutrients and the Immune SystemWorking in Harmony to Reduce the Risk of Infection. Nutrients 2020;12(1):236.

17. Kumar I, Gautam M, Srivastava D, Yadav R. Assess the Diet Diversity Score along with the availability of food variety for a rural household in the Banda and Kannauj districts of Uttar Pradesh. American International Journal of Research in Formal, Applied \& Natural Sciences 2019;25(1):14-18.

18. Siraj I, Bharti PS. 3D Printing Process: A review of recent research. SPR. 2021;1(3): 127-137.

19. Gupta R, Gupta P, Gupta S, Garg S. To evaluate the effect of Yoga intervention in reducing dental students' anxiety prior to and during a periodontic surgical procedure. SPR. 202; 1(3): 144 - 147.

20. Mukherjee A, Paul S, Saha I, Som TK, Ghose G. Dietary diversity and its determinants: A community-based study among adult population of Durgapur, West Bengal. Med J DY Patil Vidyapeeth 2018;4:296-301. 